\title{
Adsorption characteristics of an enteric virus- binding protein to norovirus, rotavirus and poliovirus
}

\author{
Takahiro Imai ${ }^{1,2+}$, Daisuke Sano ${ }^{2 *}$, Takayuki Miura ${ }^{2 \dagger}$, Satoshi Okabe ${ }^{2 \dagger}$, Keishi Wada $^{1 \dagger}$, Yoshifumi Masago ${ }^{1 \dagger}$ and \\ Tatsuo Omura ${ }^{1+}$
}

\begin{abstract}
Background: Water contamination with human enteric viruses has posed human health risks all over the world. Reasonable and facile methodologies for recovering and quantifying infectious enteric viruses in environmental samples are needed to address the issues of waterborne viral infectious diseases. In this study, a bacterial protein that has a binding capability with several enteric viruses is discovered, and its binding characteristics were investigated for utilizing it as a viral adsorbent in virus recovery and detection technologies.

Results: A gene of an enteric virus-binding protein (EVBP), derived from a monomer of a bacterial chaperon protein GroEL, was successfully acquired from a genomic DNA library of activated sludge microorganisms with nested PCR. Equilibrium dissociation constants between EVBP and norovirus-like particles (NoVLPs) of genotypes Gl.7 and Gll.4, estimated with quartz crystal microbalance method, were 240 and 210 nM, respectively. These values of equilibrium dissociation constant imply that the binding affinity between EVBP and NoVLPs is 1 to 3 -log weaker than that in general antigen-antibody interactions, but about 2-log stronger than that in weak specific interactions of proteins with cations and organic polymers. The adsorptions of EVBP to norovirus, group A rotavirus and poliovirus type 1 were found to be significant in enzyme-linked immunosorbent assay. Meanwhile, the binding of native GroEL tetradecamer to viral particles was weaker than that of EVBP, presumably because of a steric hindrance. The small molecule of EVBP could have an advantage in the access to the surface of viral particles with rugged structure.

Conclusions: EVBP that has a broad binding spectrum to enteric viruses was newly discovered. The broad binding characteristic of EVBP would allow us to utilize it as a novel adsorbent for detecting diverse enteric viruses in clinical and environmental samples.
\end{abstract}

\section{Background}

Water contamination with human enteric viruses is a growing concern, because the dissemination of human enteric viruses in reservoir, river water and seawater could pose human health risks for infectious viral diseases via drinking water $[1,2]$, recreation water [3], irrigation water [4], marine cultured products [5,6], and so on. The quantity of infectious enteric viruses in water, which has to be accurately determined for assessing

\footnotetext{
* Correspondence: dsano@eng.hokudai.ac.jp

† Contributed equally

${ }^{2}$ Division of Environmental Engineering, Faculty of Engineering, Hokkaido University, North 13, West 8, Kita-ku, Sapporo, Hokkaido, 060-8628, Japan Full list of author information is available at the end of the article
}

risks of waterborne viral diseases, is often very difficult to analyze, because of the low concentration of enteric viruses in water environments [7], the inability of molecular detection methods to distinguish infectious and non-infectious virions $[8,9]$, and the presence of inhibitory substances for the processes of genome extraction and amplification [10]. Reasonable and facile methodologies for recovering and quantifying infectious enteric viruses in environmental samples are needed to address the issues of waterborne viral infectious diseases.

One rationalized approach to collect infectious virions from environmental samples would be the employment of viral antigen recovery methods by using virus-specific antibodies [11]. The integrity of viral capsid structure,
C Biomed Central

(C) 2011 Imai et al; licensee BioMed Central Ltd. This is an Open Access article distributed under the terms of the Creative Commons Attribution License (http://creativecommons.org/licenses/by/2.0), which permits unrestricted use, distribution, and reproduction in any medium, provided the original work is properly cited. 
including antigenic sites, is prerequisite to maintain infectivity, and viral particles bound to specific antibodies might be structurally intact. However, diverse enteric viruses in Caliciviridae, Picornaviridae and Reoviridae have been recognized as waterborne agents [12], and antibody may be too specific to capture all possible strains of a target virus [13]. The preparation of an array of antibodies for each enteric virus of interest would be enormously costly and unrealistic. The discovery of alternative viral adsorbents, which have a broad binding spectrum to enteric viruses and ensure the infectivity of recovered virions, could be very valuable for accurately investigating health risks posed by infectious enteric viruses in water environments.

Virus-binding proteins, which were discovered from a bacterial culture derived from activated sludge [14], could be alternative viral adsorbents, because these bacterial proteins can stably interact with human viral particles [15]. Recently, norovirus-binding proteins (NoVBPs) were acquired with an affinity to a norovirus (NoV) capsid peptide [16]. It was expected that these NoVBPs, which are derived from homologues of a chaperonin protein GroEL, had a binding capability to several NoV genotypes, presumably because of the critical role of hydrophobic effect [16]. This feature of a broad binding spectrum has raised the expectation that the acquired NoVBPs might be utilized as adsorbents for the recovery and detection of multiple genotypes of NoV in environmental samples. Furthermore, the main contribution of hydrophobic effect might allow us to utilize these proteins as adsorbents for other enteric viruses, if non-specific interactions of these proteins with impurities in environmental samples are well excluded.

In this study, a gene of NoVBP was acquired from an extracted genomic DNA of activated sludge microorganisms, and the adsorption characteristics of the gene product (a candidate of enteric virus-binding protein: EVBP) to particles of enteric viruses were investigated. Values of the equilibrium dissociation constant were estimated with quarts crystal microbalance (QCM) method. Furthermore, the interaction between the EVBP candidate and enteric virus particles, including NoV genotypes GI.7, GII.3, GII.4, GII.6, group A rotavirus (RV-A) and poliovirus type 1 (Sabin) (PV1), was analyzed by enzyme-linked immunosorbent assay (ELISA). Based on these binding assays, the applicability of the gene product as EVBP was discussed.

\section{Results}

Production and purification of the EVBP candidate

A gene coding the candidate of EVBP was acquired from the extracted genomic DNA of activated sludge microorganisms with nested PCR [GenBank:AB618053]. The estimated molecular weight of the protein is 57
$\mathrm{kDa}$. It was confirmed by BLAST search that the isolated gene codes a homologue of a chaperonin GroEL monomer. Figure 1 shows the SDS-PAGE profile of extracted soluble proteins from $E$. coli cells transformed by $\mathrm{pDEST} 17 / \mathrm{TI} / \mathrm{EVBP}$ and the EVBP candidate purified with nickel ion-immobilized affinity chromatography. Strong expression of a protein with a molecular weight of about $60 \mathrm{kDa}$ was observed in the extracted soluble proteins from E. coli cells (Lane 1, Figure 1). This protein seemed to be histidine-tagged, because it was easily purified by nickel ion-immobilized column (Lane 2, Figure 1). These results indicate that the production and purification of the EVBP candidate were successfully performed. The recovery of the target his-tag protein as

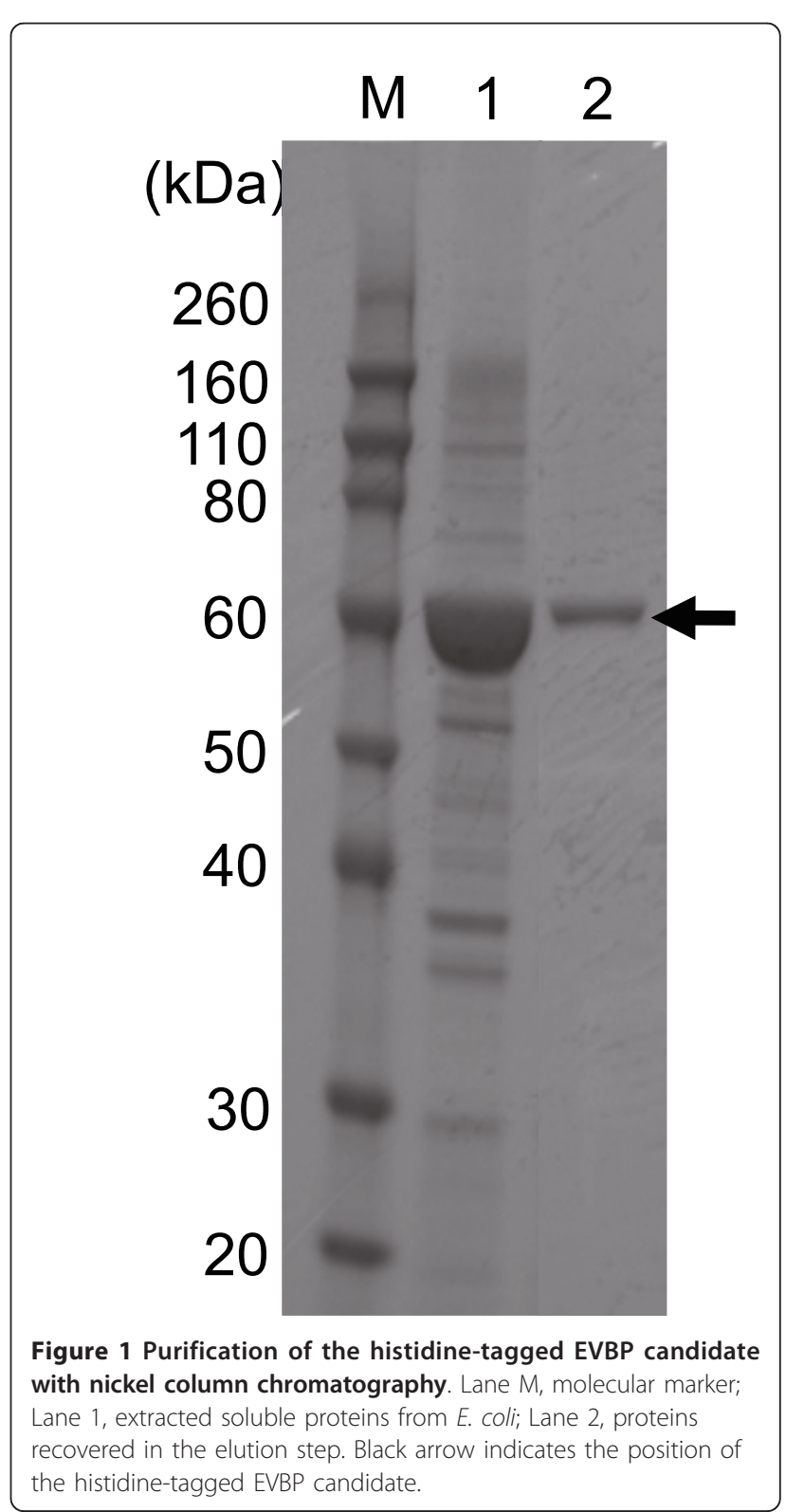


a soluble protein enormously facilitates the protein processing, because it is not necessary to purify and solubilize inclusion bodies in E. coli cells.

\section{Equilibrium dissociation constant estimated with QCM}

Figure 2 shows the equilibrium adsorption isotherm of the interaction between immobilized NoVLP (GI.7 or
GII.4) on a quartz crystal chip and the EVBP candidate, which was analyzed by QCM. The adsorption isotherm was acquired four times for each NoV genotype, and the values of the equilibrium dissociation constant in the Langmuir binding isotherm equation were estimated. As a result, the equilibrium dissociation constants of the EVBP candidate with NoV GI.7 and GII.4 were found
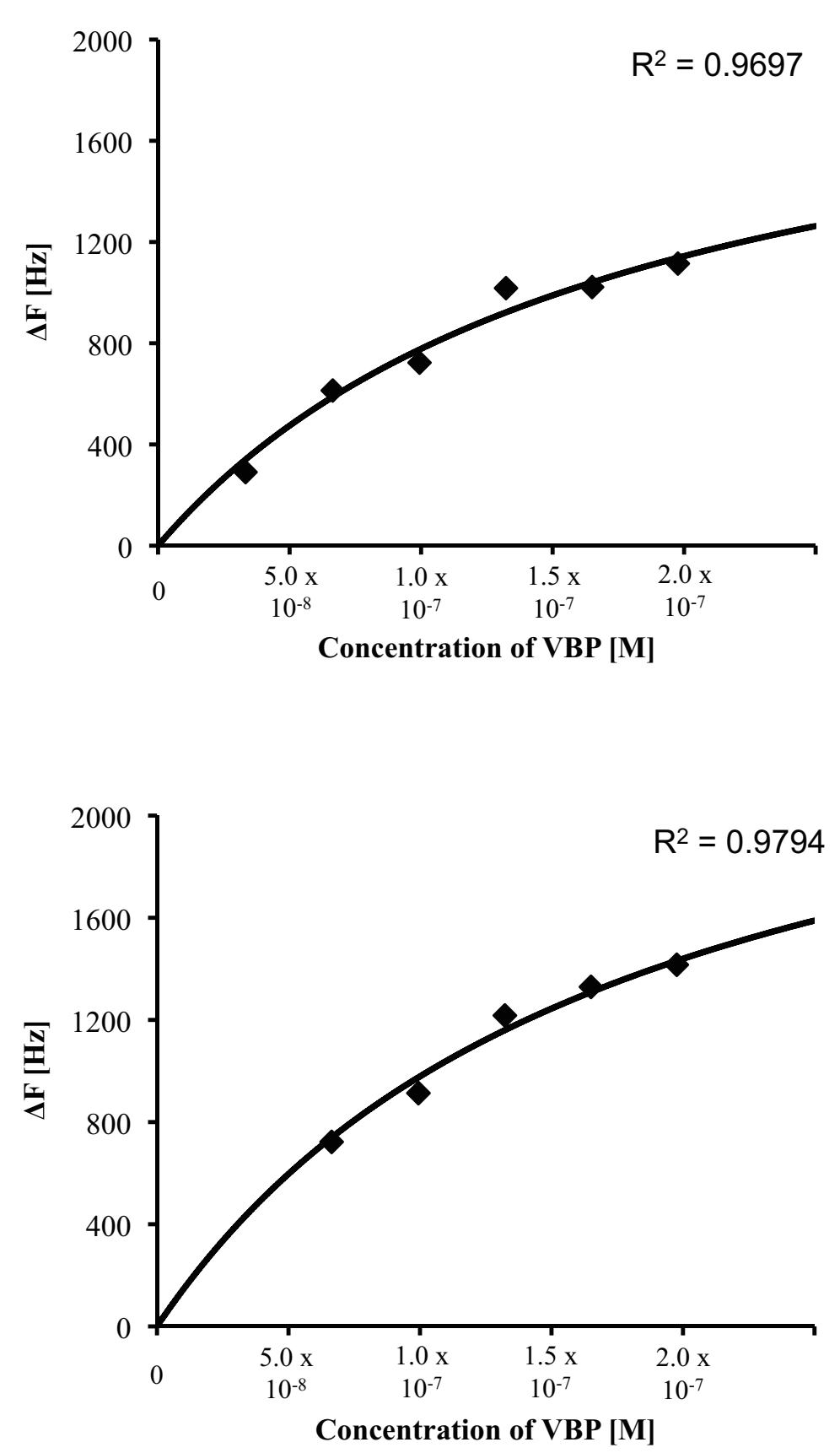

Figure 2 Equilibrium adsorption isotherm of the interaction between immobilized NoVLP on a sensor chip and EVBP, acquired with the quartz crystal microbalance method. The change of frequency (delta-F) was plotted against the concentration of EVBP added on a sensor chip where NoVLP was immobilized. A, representative delta-F spots and a regression curve for NoVLP of GI.7; B, representative delta-F spots and a regression curve for NoVLP of Gll.4. 
out to be $240 \mathrm{nM}$ (standard deviation $(\mathrm{SD})=60, \mathrm{n}=4$ ) and $210 \mathrm{nM}(\mathrm{SD}=50, \mathrm{n}=4)$, respectively. These values of the equilibrium dissociation constant imply that the binding between the EVBP candidate and NoVLP is 1 to 3 -log weaker than that in the specific interaction between antibody and antigen, which can reach $0.1 \mathrm{nM}$ [17-19]. Meanwhile, the interaction between the EVBP candidate and NoVLP is about 2-log stronger than protein adsorptions to multivalent cations and sepharose polymers, in which the dissociation constants are around several $\mu \mathrm{M}$ [20-22]. Our previous study showed that bacterial proteins with a high identity in amino acid sequence to the GroEL monomer were recovered by their affinity to $\mathrm{C}$-terminal peptide originated from $\mathrm{NoV}$ GII.4 capsid, and the hydrophobic effect was likely to be the main factor in the interaction [16]. As indicated in Figure 3, hydrophobic amino acid residues are well conserved among NoV genotypes in genogroups I (GI) and II (GII). It would be plausible that the hydrophobic region in the $\mathrm{C}$-termini of $\mathrm{NoV}$ capsid protein, which is exposed to outside of viral particle [23,24], is the binding site with the EVBP candidate. The gene product can be regarded as EVBP if it exhibits this level of binding affinity to other enteric viruses as well as to NoV.

\section{Binding assay of the EVBP candidate with enteric virus particles by ELISA}

In order to confirm the binding capability of the EVBP candidate to enteric viruses, ELISA using particles of PV1, RV-A, NoV GI.7, GII3, GII.4, and GII.6 was conducted. The binding assay of a native GroEL, a tetradecamer molecule (Sigma, Japan), was also performed in order to investigate the influence of the complex formation on virus-binding ability. The EVBP candidate and GroEL complex were biotinylated prior to the binding assays, and the binding of biotinylated proteins to immobilized viral particles was detected in ELISA with avidin carrying horseradish peroxidase.

Figure 4 shows the result of ELISA, expressed in signal/noise $(\mathrm{S} / \mathrm{N})$ ratio. The $\mathrm{S} / \mathrm{N}$ ratio larger than 1.0 means that the binding is significant, because this is the ratio of absorbance at $492 \mathrm{~nm}\left(\mathrm{~A}_{492}\right)$ in a virus-immobilized well to that in a virus-negative (bovine serum albumin (BSA)-coated) well. Values of $\mathrm{A}_{492}$ in the virusnegative well were $0.18(\mathrm{SD}=0.01)$ and $0.73(\mathrm{SD}=$ 0.07 ) for the biotinylated EVBP and GroEL-inoculated wells, respectively. The background signal caused by the interaction of the biotinylated GroEL with the blocking agent (BSA) was detected. Consequently, the EVBP candidate can bind with all virus particles tested (PV1, RVA, NoV GI.7, GII.3, GII.4, and GII.6), indicating that the product of the acquired gene can be regarded as EVBP. The hydrophobic effect could play a crucial role in the binding of EVBP with PV1 and RV-A, because PV has extensive hydrophobic surface on the north rim of the canyon on the capsid surface [25], and RV has a hydrophobic apex on the exposed surface of the virion-distal end (shoulder surface) of the spike body [26]. Meanwhile, the GroEL complex also gave positive $\mathrm{S} / \mathrm{N}$ ratios for all six viral particles but the values of $\mathrm{S} / \mathrm{N}$ ratio were always smaller than that of EVBP. The high background signal caused by the adsorption of GroEL to BSA would

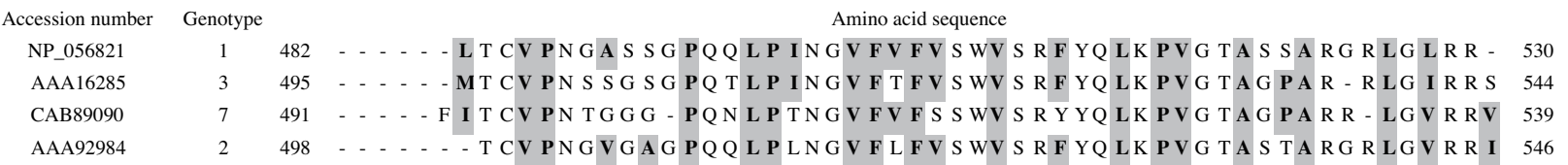

Figure 3 Multiple alignments of amino acid sequences from the C-terminal region of the norovirus (NoV) capsid protein. C-terminal regions of capsid protein from human NoV genotypes Gl.1 ([GenBank:NP_056821]), Gl.2 ([GenBank:AAA92984]), Gl.3 ([GenBank:AAA16285]), Gl.7 ([GenBank:CAB89090]), Gll.1 ([GenBank:AAB97768]), Gll.3 ([GenBank:AAB06271]), Gll.4 ([GenBank:CAA60255]), Gll.5 ([GenBank:CAB89088]), Gll.6 ([GenBank:BAC11819] and [GenBank:BAC11825]), Gll.8 ([GenBank:BAC11831] and [GenBank:AAF05820]), and Gll.12 ([GenBank:BAA84716] and [GenBank:BAC11816]) were aligned by ClustalX 2.0.10 http://mac.softpedia.com/get/Math-Scientific/ClustalX.shtml. Hydrophobic residues were indicated by grey boxes. 


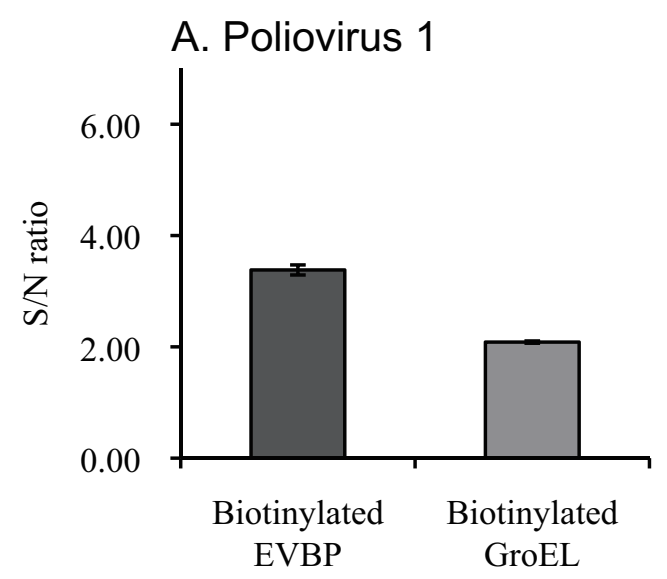

C. Norovirus GI.7

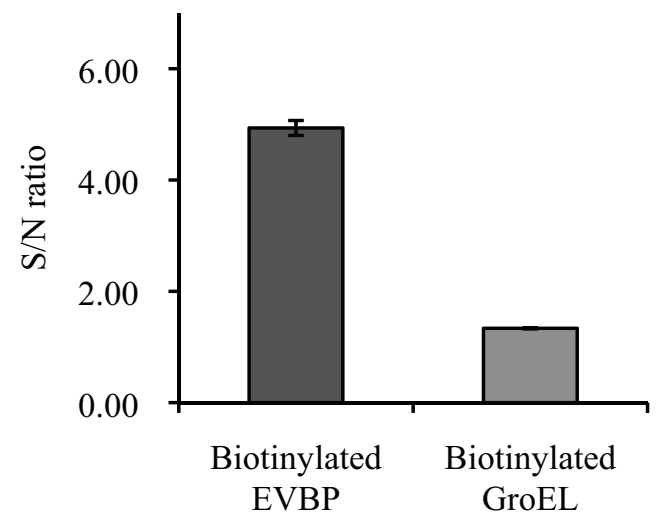

E. Norovirus GII.4

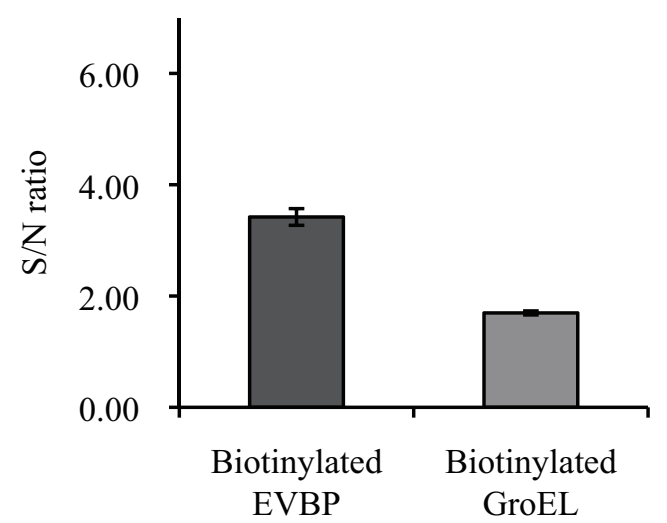

B. Rotavirus A

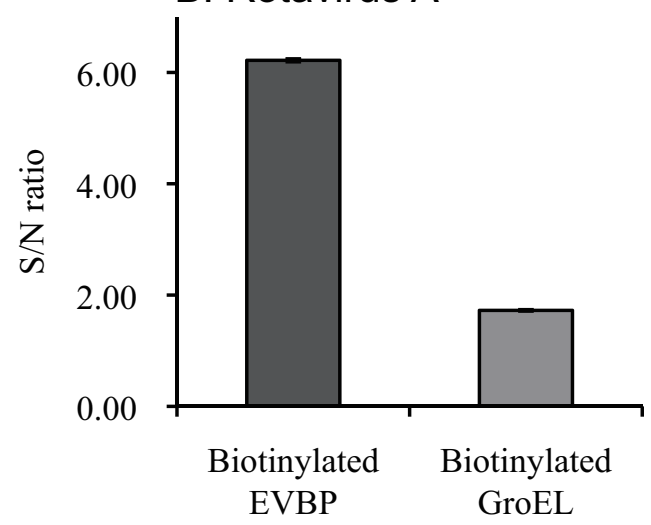

D. Norovirus GII.3

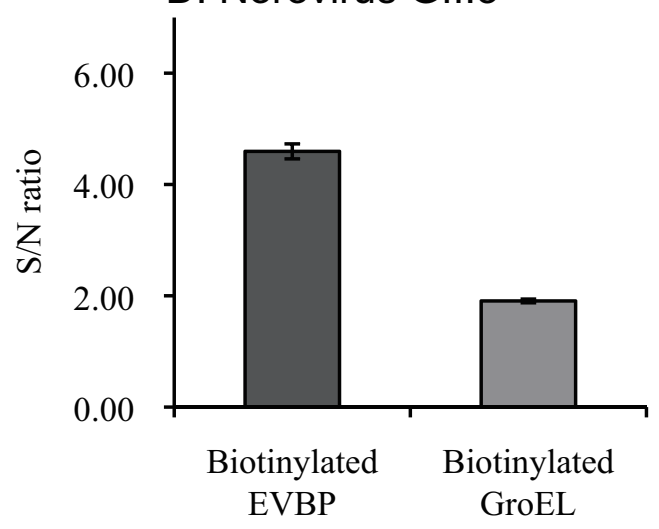

F. Norovirus GII.6

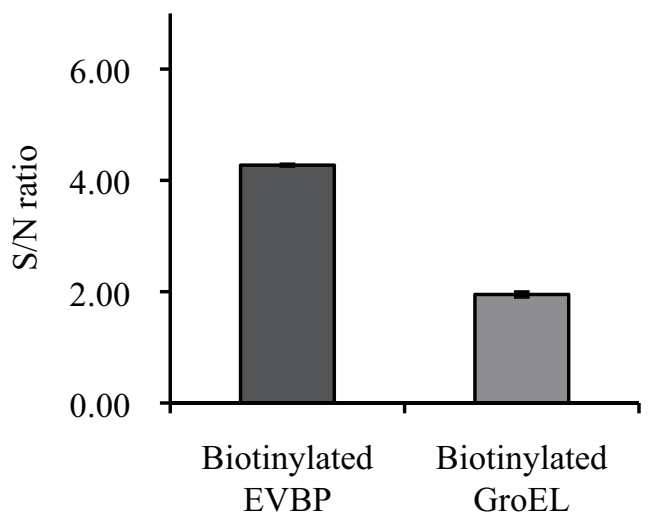

Figure 4 Binding assay of the biotinylated EVBP and the native GroEL complex with enteric virus particles. Error bars indicate the maximum and minimum values in duplicates. A, poliovirus type 1 (Sabin); B, group A rotavirus; C, NoVLP of Gl.7; D, NoVLP of GIl.3; E, NoVLP of GIl.4; F, NoVLP of Gll.6. 
be a hindrance when the GroEL is used as a viral adsorbent.

\section{Discussion}

The present study investigated the applicability of EVBP as a viral adsorbent for diverse enteric viruses in families of Picornaviridae, Caliciviridae and Reoviridae, which are dominant etiological agents of gastroenteritis cases all over the world [12]. A broad binding spectrum to human enteric viruses with a sufficient binding affinity is an indispensable binding characteristic of EVBP for utilizing it as a virus adsorbent. However, too low binding specificity is not preferred, because it would cause the non-specific adsorption of impurities co-recovered with viral particles from environmental samples, which must hamper the interaction between EVBP and viral particles.

A monomer of a chaperon protein GroEL was regarded as an EVBP candidate in this study. Figure 5 shows three dimensional model of EVBP, estimated by SWISS-MODEL, showing that hydrophobic residues are widely distributed on its surface. Meanwhile, the native GroEL complex, composed of 14 identical monomers [27], is involved in the folding of denatured proteins and de novo proteins just after translation [28]. GroEL can interact with denatured proteins that are exposing hydrophobic amino acid residues [29], thus having a relatively broad spectrum of binding to thousands of protein that have different amino acid sequences and conformations [30]. As shown in Figure 6, hydrophobic residues are also widely distributed on the surface of the native GroEL complex [31]. Since the GroEL complex can participate in the hydrophobic interactions [32], the difference in the binding affinity observed in Figure 4 could be attributable to the configurations in each protein. The C-terminal hydrophobic region of NoV capsid protein faces the hollows on the surface of the NoV particle $[23,24]$, therefore, the GroEL complex could be too large to interact with the hydrophobic region. The hollow on the NoV particle surface has a depth of $40 \AA$ and a diameter of $90 \AA$ [33], while the GroEL complex has a height of $142 \AA$ and a diameter of $140 \AA$ [34]. Since the size of canyon on the capsid surface of PV is $12 \AA$ deep and $15 \AA$ wide $[35,36]$, the steric hindrance would be also significant when the GroEL complex interacts with the hydrophobic surface of the canyon rim of PV capsid protein. The association of the GroEL complex with the shoulder surface of VP4 spike protein of RV would be also difficult, because the height of the spike is $45 \AA$ [37], about one third of the diameter of the GroEL complex molecule. The small molecule of GroEL monomer (up to several nm) must have an advantage in the access to the surface of viral particles with rugged structure.
Although the utilization of EVBP in the detection of enteric viruses from environmental samples was emphasized in this study, there are also possible applications of EVBP in virus detection from clinical samples, especially in the first screening for diagnostics of gastroenteritis. It would be possible to utilize EVBP as a ligand in chromatography and protein microarray techniques [38]. The display on bacterial cell surface [39] and the immobilization on carriers [40] could also facilitate the application of this protein as a viral adsorbent in clinical settings. The key aspect in the utilization of EVBP is to curb the non-specific interactions with impurities in clinical and environmental samples, because the hydrophobic effect is likely to be the main factor in the binding between viral particles and EVBP. Appropriate blocking reagents would be required when EVBP is utilized as a detection probe for enteric viruses. BSA was employed as a blocking reagent in the ELISA, and it was found that the binding of EVBP to BSA is negligible.

The binding spectrum of EVBP indicated in this study could be broader than that of histo-blood group antigens (HBGAs) specific to human norovirus [41], because other enteric viruses such as enterovirus and rotavirus are not using HBGAs as primary receptors on susceptible cells. The employment of porcine gastric mucin including HBGAs [42] could be able to capture other enteric viruses because of the presence of adhesive glycoproteins in mucin, although the non-specific adsorption of impurities also has to be overcome in the usage of mammalian gastric mucin as a viral adsorbent. Since $\mathrm{pH}$, ionic strength and ion composition in surrounding water are ruling the adsorption of viral particles [43], it is important to take the measure of natural substances with the propensity to adhere to EVBP in various conditions in the further study. These efforts would offer new techniques using this novel adsorbent for detecting diverse enteric viruses from clinical and environmental samples.

\section{Conclusions}

EVBP that has a broad binding spectrum to enteric viruses was newly discovered. EVBP is derived from a monomer of a bacterial chaperon protein GroEL, and this small hydrophobic protein molecule of EVBP could have an advantage in the access to the surface of viral particles with rugged structure. The broad binding characteristic of EVBP would allow us to utilize it as a novel adsorbent for detecting diverse enteric viruses in clinical and environmental samples.

\section{Methods}

\section{Test virus and cells}

Buffalo green monkey kidney (BGMK) cells and fetal rhesus monkey kidney cells (MA-104) were cultured in 


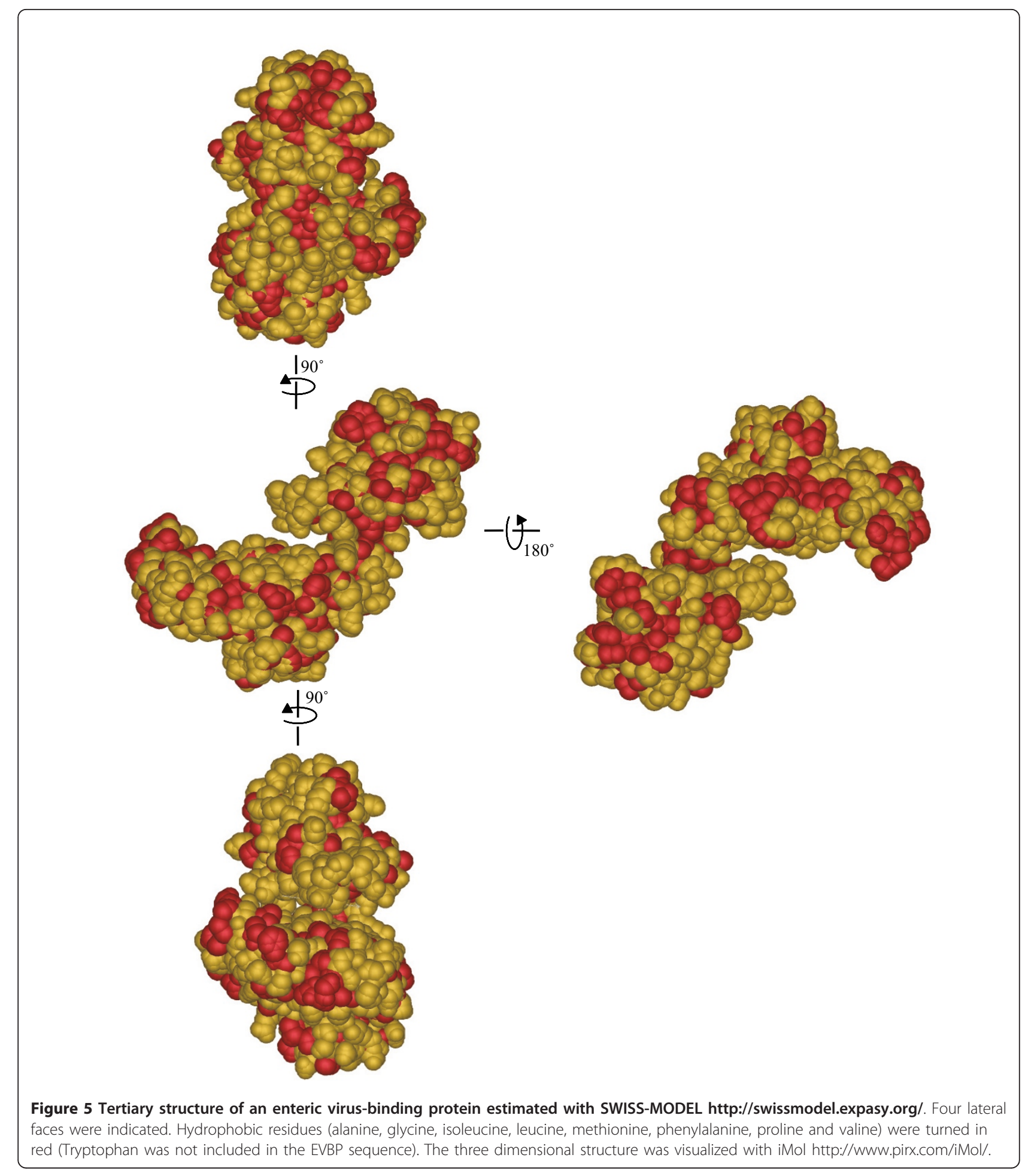

Eagle's minimal essential medium (MEM) with Earle's salts containing $10 \%$ (vol/vol) fetal bovine serum, $0.075 \%$ $\mathrm{NaHCO}_{3}, 2 \mathrm{mM}$ L-glutamine, $10 \mathrm{mM}$ nonessential amino acids, $100 \mathrm{mg} / \mathrm{ml}$ penicillin, and $100 \mathrm{U} / \mathrm{ml}$ streptomycin. Cells were grown to a confluent monolayer at $37^{\circ} \mathrm{C}$ with
$5 \% \mathrm{CO}_{2}$ in a humidifying incubator. PV1 and RV-A was propagated in BGMK and MA-104 cells for 3 to 5 days at $37^{\circ} \mathrm{C}$, respectively. PV1 was provided by Dr. Kazuyoshi Yano, Tokyo Metropolitan Institute of Public Health, Japan. RV-A was kindly supplied by Prof. Osamu 

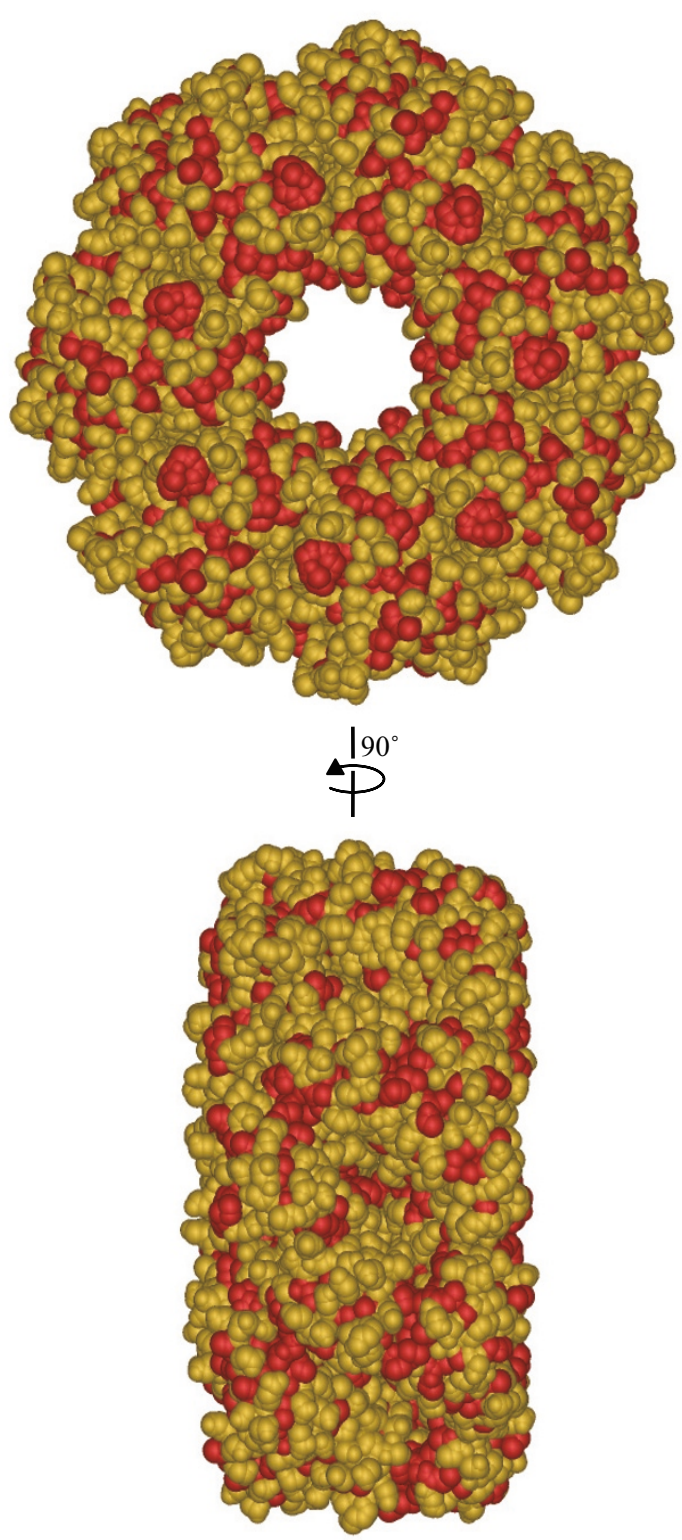

Figure 6 Tertiary structure of the GroEL complex [PDB:1S58]. Two lateral faces were indicated. Hydrophobic residues (alanine, glycine, isoleucine, leucine, methionine, phenylalanine, proline, tryptophan and valine) were turned in red. The three dimensional structure was visualized with iMol http://www.pirx.com/iMol/.

Nakagomi, Graduate School of Biomedical Sciences, Nagasaki University, Japan. Virus stock was prepared by the freeze-thaw method followed by polyethylene glycol precipitation [44] and kept in $200 \mathrm{~mL}$ aliquots at $20^{\circ} \mathrm{C}$ until use. NoVLPs of genotypes GI.7, GII.3, GII.4 and GII.6 were prepared as described elsewhere [45].
Acquisition of a gene coding a possible enteric virusbinding protein

A genomic DNA of activated sludge microorganisms was extracted as previously described [15]. Extracted genomic DNA of activated sludge microorganisms was treated with DNase-free RNase A and purified with 
phenol/chloroform and $100 \%$ ethanol. The target gene was acquired from the extracted genomic DNA of activated sludge microorganisms by nested PCR. Primers used in this study (Table 1) were designed based on the gene sequence of GroEL from Aeromonas sarmonicida (accession number: CP000644.1), because it gave 100\% identity with the $\mathrm{N}$-terminal amino acid sequences of NoVBPs isolated in our previous study [16]. PCR Master (Roche Diagnostics, Basel, Switzerland) was employed in all steps of DNA amplification. The 1st and nested PCR were run with 1 cycle of $95^{\circ} \mathrm{C}$ for $5 \mathrm{~min}, 35$ cycles of $95^{\circ} \mathrm{C}$ for $0.5 \mathrm{~min}, 50^{\circ} \mathrm{C}$ for $0.5 \mathrm{~min}$, and $72^{\circ} \mathrm{C}$ for $1 \mathrm{~min}$, and 1 cycle of $72^{\circ} \mathrm{C}$ for $10 \mathrm{~min}$. The product size of the 1st PCR is 1823, and that of the nested PCR is 1713. Results were visualized with gel electrophoresis using $1.0 \%$ agarose gels (stained with ethidium bromide) and UV light. Positive PCR bands were cut from agarose gels, and DNA was purified with GENECLEAN II KIT (Qbiogene, France). Purified products were ligated into pGEM-T Easy (Promega, WI, USA), which was used for the transformation of E. coli DH5 alpha (TaKaRa, Shiga, Japan). After cultivation at $37^{\circ} \mathrm{C}$ overnight, white colony was picked up, and the vector was extracted with Mini Prep (TaKaRa, Shiga, Japan). The sequence of the inserted PCR product was analyzed by direct sequencing of both strands of PCR product with ABI PRISM310 Genetic Analyzer (Applied Biosystems Japan Ltd., Tokyo, Japan) according to the PCR cycle sequencing big-dye terminator protocol. Based on the determined sequence, the tertiary structure was estimated with SWISS-MODEL http://swissmodel.expasy.org/[46], and visualized with iMol http://www.pirx.com/iMol/.

\section{Construction of the cloning vector for EVBP candidate}

A clone of the target gene was amplified by PCR with primers EVBP-FW and EVBP-RV (Table 1). EVBP-FW contains 5'-CACC-3' region, which is used for PCR Directional TOPO cloning (Invitrogen, CA, USA). PCR master was used for the DNA amplification. The PCR profile was run with 1 cycle of $95^{\circ} \mathrm{C}$ for $5 \mathrm{~min}, 35$ cycles of $95^{\circ} \mathrm{C}$ for $0.5 \mathrm{~min}, 50^{\circ} \mathrm{C}$ for $0.5 \mathrm{~min}$, and $72^{\circ} \mathrm{C}$ for 1

Table 1 Primers used in this study

\begin{tabular}{|c|c|c|c|c|}
\hline Primer & Sequence $\left(5^{\prime}-3^{\prime}\right)$ & Length & Position $^{a}$ & Product size \\
\hline EVBP-SP1-F & aaccgacatcctggcgattg & 20 & 658 & 1823 \\
\hline EVBP-SP1-R & caaacccagtgcacgcatac & 20 & 2480 & \\
\hline EVBP-SP2-F & cgaagcgtaatccacccttt & 20 & 679 & 1713 \\
\hline EVBP-SP2-R & agccgtttggtaaccaagac & 20 & 2391 & \\
\hline EVBP-FW & caccatggcagctaaagaag & 20 & $729^{b}$ & $1634^{c}$ \\
\hline EVBP-RV & ttacaccatgcccatgccac & 20 & 2358 & \\
\hline
\end{tabular}

a, position in the Aeromonas salmonicida chaperonin GroES and chaperonin GroEL genes, complete cds (AF030975.1); b, without 5'-cacc-3' region; c, with 5'-cacc-3' region. min, and 1 cycle of $72^{\circ} \mathrm{C}$ for $10 \mathrm{~min}$. The PCR product size is 1634. PCR product was cloned with pENTR/SD/ D-TOPO (Invitrogen Corp., Carlsbad, CA, USA). The cloned vector, $\mathrm{pENTR/KW/EVBP}$, was used for the transformation of E. coli cells (One Shot TOP10 Chemically Competent Cell, Invitrogen Corp., Carlsbad, CA, USA). The target gene in pENTR/KW/EVBP was subcloned into pDEST17 (Invitrogen Corp., Carlsbad, CA, USA) with LR reaction. The pDEST17 carrying the target gene (pDEST17/TI/EVBP) was used for the transformation of $E$. coli DH5 alpha and purified as described above.

\section{Production of EVBP candidate with $E$. coli}

Purified pDEST17/TI/EVBP was used for the transformation of E. coli BL21-AI (Invitrogen Corp., Carlsbad, CA, USA). A preculture containing the expression plasmid was grown overnight at $37^{\circ} \mathrm{C}$ in $\mathrm{LB}$ medium with ampicillin $(50 \mathrm{mg} / \mathrm{ml})$ and used to inoculate $(1 / 50) \mathrm{LB}$ medium. The culture was grown for $4 \mathrm{hrs}$ at $37^{\circ} \mathrm{C}$, and protein expression was induced by the addition of $20 \%$ $\mathrm{L}$-arabinose to a final concentration of $0.5 \%$. After overnight-growth at $37^{\circ} \mathrm{C}$, cells were immediately collected by centrifugation at $9,000 \mathrm{xg}$ for $10 \mathrm{~min}$ at $4^{\circ} \mathrm{C}$. The extraction of soluble proteins was performed by BugBuster (Novagen, Darmstadt, Germany). Histidine-tagged EVBP candidate was purified with His Trap FF crude (GE Healthcare, UK). Purified EVBP candidate was desalted by dialysis against $20 \mathrm{mM} \mathrm{NH}_{4} \mathrm{HCO}_{3}$ (pH: 8.0) at $4^{\circ} \mathrm{C}$ for at least $12 \mathrm{hr}$, and concentrated with a vacuum and centrifugal dehydrator (CVE-100, EYELA, TOKYO RIKAKIKAI CO. Ltd., Tokyo, Japan). EVBP candidate in the pellet was suspended in $100 \mu \mathrm{l}$ of double-autoclaved milliQ water, and processed for SDSPAGE and silver staining as described previously [15].

\section{Estimation of equilibrium dissociation constant}

QCM method was employed to estimate the equilibrium dissociation constant between the EVBP candidate and NoVLPs. Firstly, $50 \mu \mathrm{L}$ of NoVLP suspension of GI.7 or GII.4 in PBS at the concentration of $10^{10}$ particles $/ \mathrm{mL}$ were inoculated on the surface of a sensor chip and left for $1 \mathrm{hr}$. NoV GII.4 is employed in the QCM test because this genotype is the most important etiological agent over the world [47]. NoV GI.7 is also detected in epidemiological studies relatively frequently among NoV GI strains [48]. The sensor chip was washed with MilliQ water and installed in QCM machine (Single-Q0500, BioLab). Then, $1 \mathrm{mg} / \mathrm{ml}$ of the EVBP candidate suspended in PBS ( $\mathrm{pH}: 6.5$ ) was inoculated on the surface of a sensor chip, and the frequency of chip was recorded. The amount of the EVBP suspension inoculated on the sensor chip was changed from 1 to $8 \mu \mathrm{l}$. The equilibrium dissociation constant in Langmuir 
binding isotherm equation was estimated with the associated analytical software Q-UP.

\section{Binding assay of EVBP candidate with ELISA}

A $50 \mu \mathrm{l}$ portion of virus $\left(10^{9}\right.$ copies/well) or NoVLP $\left(10^{9}\right.$ particles/well) suspension was added to each well of a microtiter and left for $1 \mathrm{hr}$ to coat the well. Triplicate wells were used for each sample. Then, wells were washed twice with PBS and blocked with 5\% BSA in PBS. After incubation at room temperature for 2 hrs, the wells were washed twice with $\mathrm{PBS}$, and the biotinylated EVBP candidate in $50 \mu \mathrm{l}$ of PBS containing $5 \%$ BSA was applied to the wells. Plates were incubated at room temperature for $1 \mathrm{hr}$ and washed twice with PBS and then horseradish peroxidase (HRP)-modified streptavidin (Wako, Osaka, Japan) in $50 \mu \mathrm{l}$ of PBS containing $5 \%$ BSA was inoculated to each well. After incubation at room temperature for $1 \mathrm{hr}$, wells were washed four times with PBS, and HRP-modified streptavidin bound was measured by coloring with o-phenylenediamine (P7288, SIGMA CHEMICAL CO., ST. Louis, MO., USA) and $\mathrm{H}_{2} \mathrm{O}_{2}$ in citrate-phosphate buffer for $30 \mathrm{~min}$. The coloring reaction was stopped with $2 \mathrm{M} \mathrm{H}_{2} \mathrm{SO}_{4}$. The absorbance at $492 \mathrm{~nm}\left(\mathrm{~A}_{492}\right)$ was determined with a plate reader (Multiskan MS, Labsystems, Finland).

\section{Acknowledgements and Funding}

This work was funded by Grant-in-Aid for Scientific Research (S: 19106009 and Young Scientist: 20-5366) from the Japan Society for the Promotion of Science (JSPS), and Core Research for Evolutional Science and Technology, Japan Science and Technology Agency (JST).

\section{Author details}

${ }^{1}$ Department of Civil and Environmental Engineering, Graduate School of Engineering, Tohoku University, Aoba 6-6-06, Sendai, 980-8579, Japan. ${ }^{2}$ Division of Environmental Engineering, Faculty of Engineering, Hokkaido University, North 13, West 8, Kita-ku, Sapporo, Hokkaido, 060-8628, Japan.

\section{Authors' contributions}

$\mathrm{Tl}$ carried out the protein purification and the immunoassay, participated in the sequence alignment and helped to draft the manuscript. DS conceived of the study, participated in its design and coordination and drafted the manuscript. TM carried out the molecular genetic studies and the protein binding assay. SO participated in the design of the study. KW carried out the molecular genetic studies, participated in the sequence alignment. YM participated in the design of the study. TO conceived of the study, and participated in its design. All authors read and approved the final manuscript.

\section{Competing interests}

The authors declare that they have no competing interests.

Received: 27 July 2011 Accepted: 16 December 2011 Published: 16 December 2011

\section{References}

1. Haas CN, Rose JB, Gerba C, Regli S: Risk assessment of virus in drinking water. Risk Anal 1993, 13:545-552.

2. Fong TT, Lipp EK: Enteric viruses of humans and animals in aquatic environments: health risks, detection, and potential water quality assessment tools. Microbiol Mol Biol Rev 2005, 69:357-371.
3. Gerba $C P$, Rose JB, Haas CN, Crabtree KD: Waterborne rotavirus: A risk assessment. Water Res 1996, 30:2929-2940.

4. Mara DD, Sleigh PA, Blumenthal UJ, Carr RM: Health risks in wastewater irrigation: comparing estimates from quantitative microbial risk analyses and epidemiological studies. J Water Health 2007, 5(1):39-50.

5. Rose JB, Sobsey MD: Quantitative risk assessment for viral contamination of shellfish and coastal waters. J Food Protect 1993, 56(12):1043-1050.

6. Pinto RM, Costafreda MI, Bosch A: Risk assessment in shellfish-borne outbreaks of Hepatitis A. Appl Environ Microbiol 2009, 75(23):7350-7355.

7. Bosch A, Guix S, Sano D, Pinto RM: New tools for the study and direct surveillance of viral pathogens in water. Curr Opin Biotech 2008, 19:295-301.

8. Cliver DO: Capsid and infectivity in virus detection. Food Environ Virol 2009, 1:123-128.

9. Rodriguez RA, Pepper IL, Gerba CP: Application of PCR-based methods to assess the infectivity of enteric viruses in environmental samples. Appl Environ Microbiol 2009, 75(2):297-307.

10. Costafreda MI, Bosch A, Pinto RM: Development, evaluation, and standardization of a real-time TaqMan reverse transcription-PCR assay for quantification of hepatitis A virus in clinical and shellfish samples. Appl Environ Microbiol 2006, 72:3846-3855.

11. Galil KHAE, Sokkary MAE, Kheira SM, Salazar AM, Yates MV, Chen W, Mulchandani A: Combined immunomagnetic separation-molecular beacon-reverse transcription-PCR assay for detection of hepatitis $A$ virus from environmental samples. Appl Environ Microbiol 2004, 70:4371-4374.

12. Bosch $A$ : Human enteric viruses in the water environment: a minireview. Internatl Microbiol 1998, 1:191-196.

13. Mattison K, Bidawid S: Analytical methods for food and environmental viruses. Food Environ Virol 2009, 1:107-122.

14. Sano D, Matsuo T, Omura T: Virus-binding proteins recovered from bacterial culture derived from activated sludge by affinity chromatography assay using a viral capsid peptide. Appl Environ Microbiol 2004, 70(6):3434-3442.

15. Sano D, Omura T: Construction of a cloning system for the mass production of virus-binding protein for poliovirus type 1. Appl Environ Microbiol 2005, 71:2608-2615.

16. Sano D, Wada K, Imai T, Masago Y, Omura T: Norovirus-binding proteins recovered from activated sludge micro-organisms with an affinity to a noroviral capsid peptide. J Appl Microbiol 2010, 109:1923-1928.

17. Boder ET, Midelfort KS, Wittrup KD: Directed evolution of antibody fragments with monovalent femtomolar antigen-binding affinity. PNAS 2000, 97:10701-10705.

18. Howkins RE, Russel SJ, Winter G: Selection of phage antibodies by binding affinity. J Mol Biol 1992, 226:889-896.

19. Pidard D, Montgomery RR, Bennett JS, Kunicki TJ: Interaction of AP-2, a monoclonal antibody specific for the human platelet glycoprotein IIb-IIla complex, with intact platelets. J Biol Chem 1983, 258:12582-12586.

20. Hutchens TW, Yip TT, Porath J: Protein interaction with immobilized ligands: quantitative analyses of equilibrium partition data and comparison with analytical chromatographic approaches using immobilized metal affinity adsorbents. Anal Biochem 1988, 170:168-182.

21. Hutchens TW, Yip TT: Protein interactions with immobilized transition metal ions: Quantitative evaluations of variations in affinity and binding capacity. Anal Biochem 1990, 191:160-168.

22. Skidmore GL, Horstmann BJ, Chase HA: Modelling single-component protein adsorption to the cation exchanger S Sepharose FF. J Chromatogr A 1990, 498:113-128.

23. Parker TD, Kitamoto N, Tanaka T, Hutson AM, Estes MK: Identification of genogroup I and genogroup II broadly reactive epitopes on the norovirus capsid. J Virol 2005, 79:7402-7409.

24. Prasad BW, Hardy ME, Dokland T, Bella J, Rossman MG, Estes MK: X-ray crystallographic structure of the Norwalk virus capsid. Science 1999, 286:287-290.

25. He Y, Bowman VD, Mueller S, Bator CM, Bella J, Peng X, Baker TS, Wimmer E, Kuhn RJ, Rossmann MG: Interaction of the poliovirus receptor with poliovirus. PNAS 2000, 97(1):79-84.

26. Dormitzer PR, Nason EB, Prasad BBV, Harrison SC: Structural rearrangements in the membrane penetration protein of a nonenveloped virus. Nature 2004, 430:1053-1058. 
27. Kiser PD, Lodowski DT, Palczewski K: Purification, crystallization and structure determination of native GroEL from Escherichia coli lacking bound potassium ions. Acta Cryst F 2007, 63:457-461.

28. Lesk AM: Introduction to Protein Science, Architecture, Functions, and Genomics Oxford: Oxford University Press; 2004.

29. Ewalt KL, Hendrick JP, Houry WA, Hartl FU: In vivo observation of polypeptide flux through thebacterial chaperonin system. Cell 1997 90:491-500.

30. Kawata Y, Nosaka K, Hongo K, Mizobata T, Nagai J: Chaperonin GroEL and ADP facilitate the folding of various proteins and protect against heat inactivation. FEBS Lett 1994, 345:229-232.

31. Chaudhry C, Horwich AL, Brunger AT, Adams PD: Exploring the structural dynamics of the E.coli chaperonin GroEL using translation-librationscrew crystallographic refinement of intermediate states. J Mol Biol 2004, 342:229-245.

32. Marchenko NY, Marchenkov W, Kaysheva AL, Kashparov IA, Kotova NV, Kaliman PV, Semisotnov GV: Affinity chromatorgraphy of GroEL chaperonin based on denatured proteins: role of electrostatic interactions in regulation of GroEL affinity for protein substrates. Biochem 2006, 71:1357-1364.

33. Prasad BW, Hardy ME, Estes MK: Structural studies of recombinant Norwalk capsids. J Infect Dis 2000, 181:S317-S321.

34. Sigler PB, Xu Z, Rye HS, Burston SG, Fenton WA, Horwich AL: Structure and function in GroEL-mediated protein folding. Annu Rev Biochem 1998, 67:581-608.

35. Hogle JM, Chow M, Filman DJ: Three-dimensional structure of poliovirus at $2.9 \AA$ resolution. Science 1985, 229:1358-1365.

36. Racaniello VR: Early events in poliovirus infection: Virus-receptor interactions. PNAS 1996, 93:11378-11381.

37. Prasad BW, Burns JW, Marietta E, Estes MK, Chiu W: Localization of VP4 neutralization sites in rotavirus by three-dimensional cryo-electron microscopy. Nature 1990, 343:476-479.

38. Quiel A, Jurgen B, Piechotta G, Le Foll AP, Ziebandt AK, Kohler C, Koster D, Engelmann S, Erck C, Hintsche R, Wehland J, Hecker M, Schweder T: Electrical protein array chips for the detection of staphylococcal virulence factors. Appl Microbiol Biotechnol 2010, 85:1619-1627.

39. Jose J: Autodisplay: efficient bacterial surface display of recombinant proteins. Appl Microbiol Biotechnol 2006, 69:607-614.

40. Xiao X, Yang X, Liu T, Chan Z, Chen L, Li H, Deng L: Preparing a highly specific inert immunomolecular-magnetic beads for rapid detection and separation of S. aureus and group G Streptococcus. Appl Microbiol Biotechnol 2007, 75:1209-1216.

41. Cannon JL, Vinjé J: Histo-blood group antigen assay for detecting noroviruses in water. Appl Environ Microbiol 2008, 74:6818-6819.

42. Tian P, Engelbrektson A, Mandrell R: Two-log increase in sensitivity for detection of norovirus in complex samples by concentration with porcine gastric mucin conjugated to magnetic beads. Appl Environ Microbiol 2008, 74:6818-6819.

43. Da Silva AK, Kavanagh OV, Estes MK, Elimelech M: Adsorption and aggregation properties of norovirus GI and Gll virus-like particles demonstrate differing responses to solution chemistry. Environ Sci Tech 2011, 45:520-526.

44. Lewis GD, Metcalf TG: Polyethylene glycol precipitation for recovery of pathogenic viruses, including Hepatitis A Virus and human Rotavirus, from oyster, water and sediment samples. Appl Environ Microbiol 1998, 54:1983-1988.

45. Kitamoto N, Tanaka T, Natori K, Takeda N, Nakata S, Jiang X, Estes MK: Cross-reactivity among several recombinant calicivirus virus-like particles (VLPs) with monoclonal antibodies obtained from mice immunized orally with one type of VLP. J Clin Microbiol 2002, 40:2459-2465.

46. Arnold K, Bordoli L, Kopp J, Schwede T: The SWISS-MODEL Workspace: A web-based environment for protein structure homology modelling Bioinformatics 2006, 22:195-201.

47. Siebenga JJ, Lemey P, Pond SLK, Rambaut A, Vennema H, Koopmans M: Phylodynamic reconstruction reveals Norovirus Gll.4 epidemic expansions and their molecular determinants. PLoS Pathog 2010, 6: e1000884.

48. Medici MC, Martinelli M, Abelli LA, Ruggeri FM, Di Bartolo I, Arcangeletti MC, Pinardi F, De Conto F, lzzi G, Bernasconi S, Chezzi C, Dettori G: Molecular epidemiology of Norovirus infections in sporadic cases of viral gastroenteritis among children in northern Italy. J Med Virol 2006, 78:1486-1492.

doi:10.1186/1472-6750-11-123

Cite this article as: Imai et al: Adsorption characteristics of an enteric virus-binding protein to norovirus, rotavirus and poliovirus. BMC Biotechnology 2011 11:123.

\section{Submit your next manuscript to BioMed Central and take full advantage of:}

- Convenient online submission

- Thorough peer review

- No space constraints or color figure charges

- Immediate publication on acceptance

- Inclusion in PubMed, CAS, Scopus and Google Scholar

- Research which is freely available for redistribution

Submit your manuscript at www.biomedcentral.com/submit
Biomed Central 